\title{
High-dose radiotherapy is associated with better local control of bone metastasis from hepatocellular carcinoma
}

\author{
In-Hye Jung ${ }^{1}$, Sang Min Yoon ${ }^{1}$, Jungwon Kwak ${ }^{1}$, Jin-Hong Park ${ }^{1}$, Si Yeol Song ${ }^{1}$, \\ Sang-Wook Lee ${ }^{1}$, Seung Do Ahn ${ }^{1}$, Eun Kyung Choi ${ }^{1}$, Jong Hoon Kim ${ }^{1}$ \\ ${ }^{1}$ Department of Radiation Oncology, Asan Medical Center, University of Ulsan College of Medicine, Seoul, Republic of Korea \\ Correspondence to: Sang Min Yoon, email: drsmyoon@amc.seoul.kr
}

Keywords: hepatocellular carcinoma, bone metastasis, palliative treatment, radiotherapy, dose-response relationship

Received: June 15, 2016

Accepted: January 16, 2017

Published: January 27, 2017

\section{ABSTRACT}

We evaluated the pain and radiologic response, time to progression, and dose-response relationship after palliative radiotherapy for bone metastasis from hepatocellular carcinoma. We retrospectively reviewed the medical records of 91 patients between January 2004 and August 2012. The reviewed medical records included data on changes in pain, local tumor progression, and radiologic response evaluated via follow-up images. The radiologic response was assessed based on the Response Evaluation Criteria In Solid Tumors. The pain response was defined according to the International Bone Metastases Consensus Working Party palliative radiotherapy endpoints. Median radiation dose was $40 \mathrm{~Gy}$ (range, 20-66 Gy), with various fraction sizes (range, 2.0-6.0 Gy). Pain response rate was $81.4 \%$. During the follow-up periods, radiologic local tumor progression was found in 42 patients $(46.2 \%)$. The median time to progression was 14.1 months. When the patients were divided into two groups according to their radiation dose ( $<55 \mathbf{G y}_{10}$ vs. $\geq 55 \mathbf{G y}_{10}$ ), the pain response rates of the high- and low-dose groups did not differ significantly $(p=0.728)$. However, the radiologic response rate and the time to progression showed significant differences between the two groups $(p=0.009$ and $p=0.018$, respectively). With dose escalation, higher radiologic response rates and a longer time to progression were achieved in patients with mass-forming bone metastases from hepatocellular carcinoma.

\section{INTRODUCTION}

Hepatocellular carcinoma (HCC) is the sixth most common cancer and the third leading cause of cancerrelated mortality worldwide $[1,2]$. Unfortunately, the prognosis of this disease is still poor, with most patients suffering from both chronic hepatitis and frequent tumor recurrence. Moreover, extrahepatic metastasis is common and is being observed more frequently due to improved diagnostic methods and prolonged patient survival [3]. The most frequent extrahepatic metastasis site is the lung, followed by bone, lymph nodes, and adrenal gland. Bone metastasis in HCC occurs in $25-39 \%$ of patients with extrahepatic metastasis $[3,4]$.

Generally, radiotherapy is the treatment of choice for uncomplicated symptomatic bone metastases. Many prospective randomized studies and meta-analyses reported that there were no significant differences in pain control after various radiotherapy regimens; nevertheless, whereas only $2-9 \%$ of patients treated with a multifraction regimen required repeated radiotherapy, up to $28 \%$ of patients treated with a single fraction regimen required repeated radiotherapy [5-9]. In terms of pain relief, most previous studies failed to show a doseresponse relationship, but the sites of primary tumors from these studies were mainly prostate, breast, and lung cancers, not HCC [5, 7-10].

Bone metastasis from $\mathrm{HCC}$ is characterized by soft-tissue expansion with abundant vascular component $[10,11]$. It is thought that a higher radiation dose can result in better local control of these mass-forming bone metastases. According to previous studies, HCC shows a dose-response relationship to radiation, which indicates that total dose is the most important factor in tumor response [12]. In light of this fact, some researchers also studied dose-escalation for bone metastasis from HCC 
and reported a better radiologic response as well as local control when patients were given higher radiation doses to the metastatic sites $[13,14]$. However, only limited data have been reported on the duration of radiologic response after radiotherapy. Therefore, in this study, we evaluated the dose-response relationship, time to progression, and tumor control probability in order to recommend an optimal radiotherapy dose for bone metastasis from HCC.

\section{RESULTS}

\section{Patient characteristics}

The median follow-up duration was 22.8 months (range, 11.9-82.3 months). Of the 91 patients in our study population, 86 died during the follow-up due to HCC progression. The median age at the diagnosis of bone metastasis was 55 years (range, 37-79 years). Twenty-one patients $(30.8 \%)$ were diagnosed with bone metastasis at the time of diagnosis of HCC. The median duration from the diagnosis of HCC to the diagnosis of bone metastasis was 10.0 months (range, 0-172.2 months). The mean tumor diameter was $4.0 \mathrm{~cm}$ (range, $1.5-13.3 \mathrm{~cm}$ ). A massforming tumor was found in 87 patients $(95.6 \%)$. The most common site of the bone metastases was the spine, followed by the ribs and the pelvis. More detailed patient characteristics are listed in Table 1.

\section{Radiotherapy and other treatments}

Radiotherapy was planned using 2D $(n=16$, $17.6 \%)$ and $3 \mathrm{D}$ conformal radiotherapy $(n=74,81.3 \%)$ or intensity-modulated radiotherapy (IMRT) $(n=1,1.1 \%)$. The median prescription dose was 40 Gy (range, 20-66 Gy), and the median fraction size was 3 Gy (range, 2-6 Gy). Because the fraction sizes varied among patients, we analyzed the biologically equivalent dose (BED) for correction of different fraction sizes. The median BED of the total irradiation dose was 50.7 Gy (range, 28-85.3 Gy, $\alpha / \beta=10$, Table 2 ).

The patients were divided into two dose groups depending on their total dose. The patients with a radiation dose higher than 55 Gy $\mathrm{BED}_{10}$ were designated as the high-dose group $(n=45,49.5 \%)$, and the other patients were designated as the low-dose group $(n=46,50.5 \%)$. The detailed patients' characteristics by dose group are presented in Table 1 . There were no significantly different characteristics between the two groups, except for radiotherapy sites and tumor sizes.

Eleven patients $(12.1 \%)$ were administered with sorafenib before or after radiotherapy as a systemic treatment. Among them, 5 patients belonged to the lowdose group and the others belonged to the high-dose group.

\section{Pain response}

Of the 91 patients, pain response was assessed in 59 patients $(64.8 \%)$ because 26 patients did not experience pain before radiotherapy, and the change in pain scores could not be assessed in 6 patients owing to the lack of medical records. The median NRS was 3 (range, 1-10). After the radiotherapy, symptomatic pain was reduced in 48 patients $(81.4 \%)$. The detailed changes in pain score are summarized in Table 3. The pain response rates of the high-dose and low-dose groups did not significantly differ $(p=0.73)$, and these response rates are not significantly different according to the GTV volume (GTV $\leq 26 \mathrm{~mm}^{3} \mathrm{vs}$. $\left.\mathrm{GTV}>26 \mathrm{~mm}^{3}, p=0.668\right)$. However, all of the patients who experienced progressive pain were in the low-dose group (total dose: 20-39 Gy and $\mathrm{BED}_{10}$ : 28-50.7 Gy).

\section{Radiologic response and time to progression}

The radiologic responses were evaluated in all of the patients. The radiologic response rate after radiotherapy was $53.9 \%$ and the best radiologic response rates are summarized in Table 4. The radiologic responses of the two dose groups differed significantly $(p=0.009)$. The median time to the best radiologic response was 4.9 months (range, 0.7-15.3 months). In univariate and multivariate analyses of prognostic factors for radiologic response, location of bone metastasis and chemotherapy were statistically significant factors (Table 5).

Local tumor progression was observed in 42 patients (46.2\%). In the high-dose group, 15 patients (33.3\%) showed local progression, whereas in the low-dose group, 27 patients $(58.7 \%)$ experienced local tumor progression $(p=0.015)$.

The median time to progression for all patients was 14.1 months (range, 0.7-82.0 months). The time to progression significantly differed between the dose groups. The median time to progression in the high-dose group was 16.8 months (range, 1.2-82.0 months), and in the low-dose group, 11.3 months (range, 0.7-42.3 months) $(p=0.016)$ (Figure 1).

The radiologic response rates and the median time to progression did not differ significantly by GTV volume $\left(\mathrm{GTV} \leq 26 \mathrm{~mm}^{3}\right.$ vs. GTV $>26 \mathrm{~mm}^{3}, p=0.284, p=0.317$, respectively). However, the relationship between radiologic response and location of tumors was statistically significant (Table 5), and time to progression was marginally significant according to the location of bone metastasis (Figure 2).

\section{Tumor control probability}

Figure 3 shows the TCP of the total radiation dose $\left(\mathrm{BED}_{10}\right)$ versus the progression-free survival 12 months after the radiotherapy for all patients (fitted parameters: $\gamma=1.12, \mathrm{D}_{50}=41.6 \mathrm{~Gy}_{10}$, and 95\% CI, 39.1-44.1 $\left.\mathrm{Gy}_{10}\right)$. 


\begin{tabular}{|c|c|c|c|c|}
\hline \multirow[t]{2}{*}{ Characteristics } & \multicolumn{3}{|c|}{ No. of patients (\%) } & \multirow{2}{*}{$P$-value } \\
\hline & Total $(n=91)$ & High-dose $^{\text {a }}(n=45)$ & Low-dose $^{b}(n=46)$ & \\
\hline Age (years) & & & & 0.683 \\
\hline Median & 55 & 55 & 54 & \\
\hline Range & $37-79$ & $37-72$ & $37-79$ & \\
\hline Gender & & & & 0.321 \\
\hline Male & $80(87.9)$ & $38(84.4)$ & $42(91.3)$ & \\
\hline Female & $11(12.1)$ & $7(15.6)$ & $4(8.7)$ & \\
\hline ECOG PS & & & & 0.204 \\
\hline $0-1$ & $84(92.3)$ & $43(92.6)$ & $41(89.1)$ & \\
\hline $2-3$ & $7(7.7)$ & $2(4.4)$ & $5(10.9)$ & \\
\hline Child-Pugh class & & & & 0.417 \\
\hline A & $83(91.2)$ & $42(93.3)$ & $41(89.1)$ & \\
\hline B & $7(7.7)$ & $3(6.7)$ & $4(8.7)$ & \\
\hline $\mathrm{C}$ & $1(1.1)$ & - & $1(2.2)$ & \\
\hline Alpha-fetoprotein (ng/mL) & & & & 0.322 \\
\hline Median & 77.0 & 101.0 & 34.9 & \\
\hline Range & $1.0-540,277$ & $1.0-470,000$ & $2.0-540,277$ & \\
\hline Intrahepatic control & & & & 0.372 \\
\hline Yes & $67(73.6)$ & $33(73.3)$ & $34(73.9)$ & \\
\hline No & $24(26.4)$ & $12(26.7)$ & $12(26.1)$ & \\
\hline Other extrahepatic metastasis & & & & 0.236 \\
\hline Yes & $29(31.9)$ & $17(37.8)$ & $12(26.1)$ & \\
\hline No & $62(68.1)$ & $28(62.2)$ & $34(73.9)$ & \\
\hline Location & & & & $<0.001$ \\
\hline Spine & $35(38.5)$ & $6(13.3)$ & $29(63.0)$ & \\
\hline Rib & $30(33.0)$ & $18(40.0)$ & $12(26.1)$ & \\
\hline Pelvis & $19(20.9)$ & $15(33.4)$ & $4(8.7)$ & \\
\hline $\mathrm{Etc}^{\mathrm{c}}$ & $7(7.6)$ & $6(13.3)$ & $1(2.2)$ & \\
\hline Tumor size $(\mathrm{cm})$ & & & & 0.003 \\
\hline Mean diameter & 4.0 & 4.9 & 3.9 & \\
\hline Range & $1.5-13.3$ & $2.0-13.3$ & $1.5-9.0$ & \\
\hline Pathologic fracture & & & & 0.913 \\
\hline Yes & $48(42.7)$ & $24(53.3)$ & $24(52.2)$ & \\
\hline No & $43(47.3)$ & $21(46.7)$ & $22(47.8)$ & \\
\hline
\end{tabular}

Abbreviations: ECOG PS, Eastern Cooperative Oncology Group performance status.

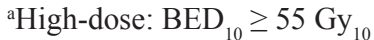

'Low-dose: $\mathrm{BED}_{10}<55 \mathrm{~Gy}_{10}$

${ }^{\mathrm{c}}$ The Etc sites included the skull, scapula, clavicle, and sternum. 
Table 2: Summary of the prescribed radiation dose

\begin{tabular}{cccc}
\hline Radiation dose & \multicolumn{1}{c}{ Median (range) } \\
\cline { 2 - 4 } & $\begin{array}{c}\text { Total } \\
(\boldsymbol{n}=\mathbf{9 1})\end{array}$ & $\begin{array}{c}\text { High-dose } \\
(\boldsymbol{n}=\mathbf{4 5})\end{array}$ & $\begin{array}{c}\text { Low-dose } \\
(\boldsymbol{n}=\mathbf{4 6})\end{array}$ \\
\hline Total dose $(\mathrm{Gy})$ & $40.0(20.0-66.0)$ & $50.0(40.0-66.0)$ & $39.0(20.0-40.0)$ \\
BED $_{10}$ & $50.7(28.0-85.3)$ & $62.5(56.0-85.3)$ & $50.0(28.0-50.7)$ \\
EQD2 & $42.3(23.3-71.0)$ & $52.1(46.7-71.0)$ & $41.7(23.3-42.3)$ \\
Fraction size (Gy) & $3.0(2.0-6.0)$ & $3.0(2.0-6.0)$ & $3.0(3.0-4.0)$ \\
\hline
\end{tabular}

Abbreviations: BED, biologically equivalent dose; EQD2, Equivalent dose in 2 Gy fractions.

Table 3: Pain responses according to changes in numeric rating scale scores before and after radiotherapy

\begin{tabular}{|c|c|c|c|c|}
\hline Response & $\begin{array}{l}\text { No. of patients }(\%) \\
\qquad(n=91)\end{array}$ & $\begin{array}{l}\text { Pre-RT NRS score } \\
\quad(\text { mean } \pm \text { SD })\end{array}$ & $\begin{array}{l}\text { Post-RT NRS score } \\
\quad(\text { mean } \pm \text { SD })\end{array}$ & $\begin{array}{c}\text { Change of NRS }{ }^{a} \\
\quad(\text { mean } \pm \text { SD })\end{array}$ \\
\hline $\mathrm{CR}$ & $24(26.4)$ & $4.0 \pm 02$ & $0.0 \pm 0.0$ & $-4.0 \pm 1.7$ \\
\hline PR & $24(26.4)$ & $5.4 \pm 1.9$ & $1.4 \pm 0.6$ & $-4.0 \pm 2.0$ \\
\hline $\mathrm{SD}$ & $7(7.7)$ & $4.0 \pm 2.0$ & $3.7 \pm 1.4$ & $-0.3 \pm 0.8$ \\
\hline PD & $4(4.4)$ & $2.8 \pm 1.3$ & $5.3 \pm 1.7$ & $+2.5 \pm 0.6$ \\
\hline $\mathrm{N} / \mathrm{A}$ & $32(35.1)$ & - & - & - \\
\hline
\end{tabular}

Abbreviations: NRS, numeric rating scale; CR, complete response; PR, partial response; SD, stable disease; PD, progressive disease; N/A, not assessed.

${ }^{a} P$-values of the changes of NRS using one-way ANOVA : overall, $p<0.001$; CR vs. PR, $p=1.000 ; \mathrm{CR}$ vs. SD, $p<0.001$;

CR vs. PD, $p<0.001$; PR vs. SD, $p<0.001$; PR vs. PD, $p<0.001$; $\mathrm{SD}$ vs. PD, $p=0.063$.

Table 4: Best radiologic response by dose group

\begin{tabular}{lcccc}
\hline Response & \multicolumn{3}{c}{ No. of patients (\%) } & \multirow{P}{*}{-value } \\
\cline { 2 - 4 } & $\begin{array}{c}\text { Total } \\
(\boldsymbol{n}=\mathbf{9 1})\end{array}$ & $\begin{array}{c}\text { High-dose } \\
(\boldsymbol{n}=\mathbf{4 5})\end{array}$ & $\begin{array}{c}\text { Low-dose } \\
(\boldsymbol{n}=\mathbf{4 6})\end{array}$ & 0.009 \\
\hline CR & $5(5.5)$ & $4(8.9)$ & $1(2.2)$ & \\
PR & $44(48.3)$ & $26(57.8)$ & $18(39.1)$ & \\
SD & $38(41.8)$ & $14(31.1)$ & $24(52.2)$ & \\
PD & $4(4.4)$ & $1(2.2)$ & $3(6.5)$ & \\
\hline
\end{tabular}

Abbreviations: CR, complete response; PR, partial response; SD, stable disease; PD, progressive disease. 
Table 5: Prognostic factors for radiologic response

\begin{tabular}{|c|c|c|c|c|c|}
\hline \multirow{2}{*}{ Variable } & \multirow{2}{*}{$\begin{array}{c}\text { No. of patients } \\
(\%)\end{array}$} & \multicolumn{2}{|c|}{ Univariate analysis } & \multicolumn{2}{|c|}{ Multivariate analysis } \\
\hline & & C. OR $(95 \%$ CI) & $P$-value & A. OR $(95 \%$ CI $)$ & $P$-value \\
\hline Gender & & $1.033(0.291-3.661)$ & 0.960 & & \\
\hline Male & $80(87.9)$ & & & & \\
\hline Female & $11(12.1)$ & & & & \\
\hline Age & & $0.720(0.314-1.649)$ & 0.437 & & \\
\hline$\leq 55$ years & $48(52.7)$ & & & & \\
\hline$>55$ years & $43(47.3)$ & & & & \\
\hline Viral etiology & & $0.450(0.171-1.183)$ & 0.105 & & \\
\hline $\operatorname{HBsAg}(+)$ & $68(74.7)$ & & & & \\
\hline HBsAg $(-)$ & $23(25.3)$ & & & & \\
\hline ECOG PS & & $0.315(0.058-1.716)$ & 0.182 & & \\
\hline $0-1$ & $84(92.3)$ & & & & \\
\hline $2-3$ & $7(7.7)$ & & & & \\
\hline Child-Pugh class & & $1.184(0.227-5.057)$ & 0.819 & & \\
\hline A & $83(91.2)$ & & & & \\
\hline $\mathrm{B}, \mathrm{C}$ & $8(8.8)$ & & & & \\
\hline Alpha-fetoprotein & & $1.748(0.673-4.540)$ & 0.251 & & \\
\hline$\leq 7.5 \mathrm{ng} / \mathrm{mL}$ & $23(25.3)$ & & & & \\
\hline$>7.5 \mathrm{ng} / \mathrm{mL}$ & $68(74.7)$ & & & & \\
\hline Other metastasis & & $1.082(0.446-2.622)$ & 0.862 & & \\
\hline No & $62(68.1)$ & & & & \\
\hline Yes & $29(31.9)$ & & & & \\
\hline Location & & $4.606(1.858-11.416)$ & 0.001 & $5.339(2.056-13.863)$ & 0.001 \\
\hline Spine & $35(38.5)$ & & & & \\
\hline Non-spine & $56(61.5)$ & & & & \\
\hline Chemotherapy & & $0.156(0.032-0.769)$ & 0.022 & $0.119(0.022-0.631)$ & 0.012 \\
\hline No & $80(87.9)$ & & & & \\
\hline Yes & $11(12.1)$ & & & & \\
\hline GTV volume & & $1.243(0.545-2.839)$ & 0.605 & & \\
\hline$\leq 26 \mathrm{~mm}^{3}$ & $45(49.5)$ & & & & \\
\hline$>26 \mathrm{~mm}^{3}$ & $46(50.5)$ & & & & \\
\hline
\end{tabular}

Abbreviations: C. OR, crude odds ratio; CI, confidence interval; A. OR, adjusted odds ratio; HBsAg, hepatitis B surface antigen; ECOG PS, Eastern Cooperative Oncology Group performance status; GTV, gross tumor volume.

According to this TCP curve, $52.8 \mathrm{~Gy}_{10}$ provides a $70 \%$ local control rate 12 months after radiotherapy.

\section{Toxicities}

The incidence of treatment-related toxicities did not differ significantly between the dose groups. Grade 4 or 5 toxicities were not observed in either group. The most common toxicities were Grade 1 anemia and thrombocytopenia. Grade hematologic 3 toxicities did occur. The details of the toxicities are shown in Table 6. Considering that many of the patients had poor liver function, other treatment modalities such as chemotherapy might have influenced their hematopoietic function. In patients with Grade 3 hematologic toxicities, 16 (69.6\%) underwent radiotherapy 1-2 months after trans-arterial chemoembolization. Grade 3 hematologic complications associated purely with radiotherapy were detected in 3 patients. Radiation-induced myelopathy and gastrointestinal bleeding were not observed during the follow-up period. 


\section{DISCUSSION}

The incidence of bone metastasis from $\mathrm{HCC}$ has been reported to be up to $40 \%$ [3]. Bone metastases often cause a great deal of discomfort such as pain or associated neurologic symptoms. For a selected group of patients with pathologic fractures or spinal cord compression with progressive symptoms, surgery is a better treatment modality because it quickly relieves neurologic symptoms. However, radiotherapy is generally the treatment of choice for uncomplicated bone metastases due to its noninvasiveness and convenience.

Previously, many randomized controlled trials have been conducted to identify an adequate dose for palliation of bone metastasis [5-7, 9, 19]. These trials have demonstrated the equivalence of multiple- and single- fraction radiotherapy schedules despite different inclusion criteria and primary end-points. Meta-analyses have also reported similar overall pain response rates of about $60 \%$ regardless of radiotherapy fractionation schedule [20-22]. The Radiation Therapy Oncology Group (RTOG) reported that they could not confirm dose-response relationships in bone metastasis despite an increased fraction size in 2011 [8]. However, the primary organs in the RTOG reports were mostly the prostate, lung, and breast; therefore, the aforementioned results could not be directly applied to other types of bone metastasis such as mass-forming metastasis. Unlike other forms of metastasis, bone metastases from HCC are usually mass-forming types with invasion of surrounding soft tissues [23, 24]. These features suggest that a higher radiation dose may be necessary to achieve better outcomes, similar to primary

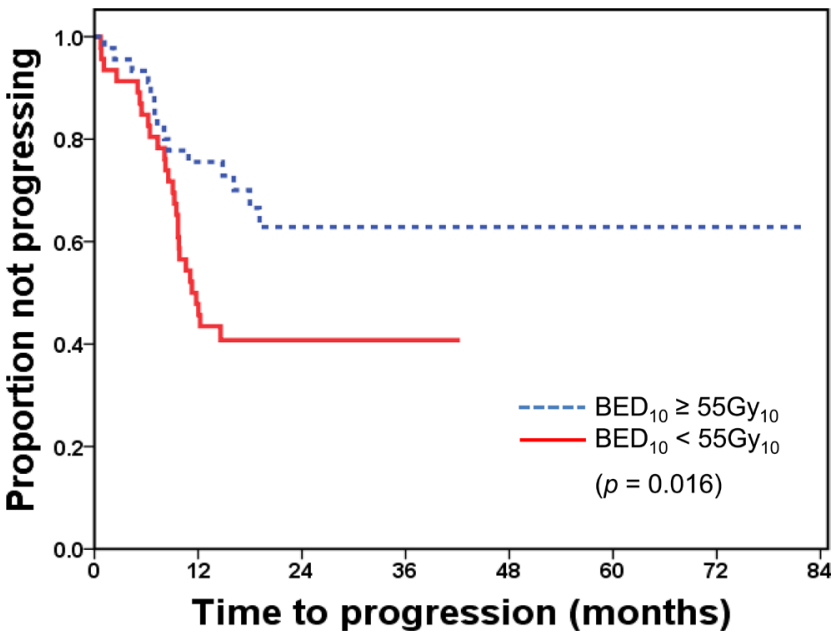

Figure 1: Time to progression after radiotherapy by dose group BED, biologically equivalent dose.

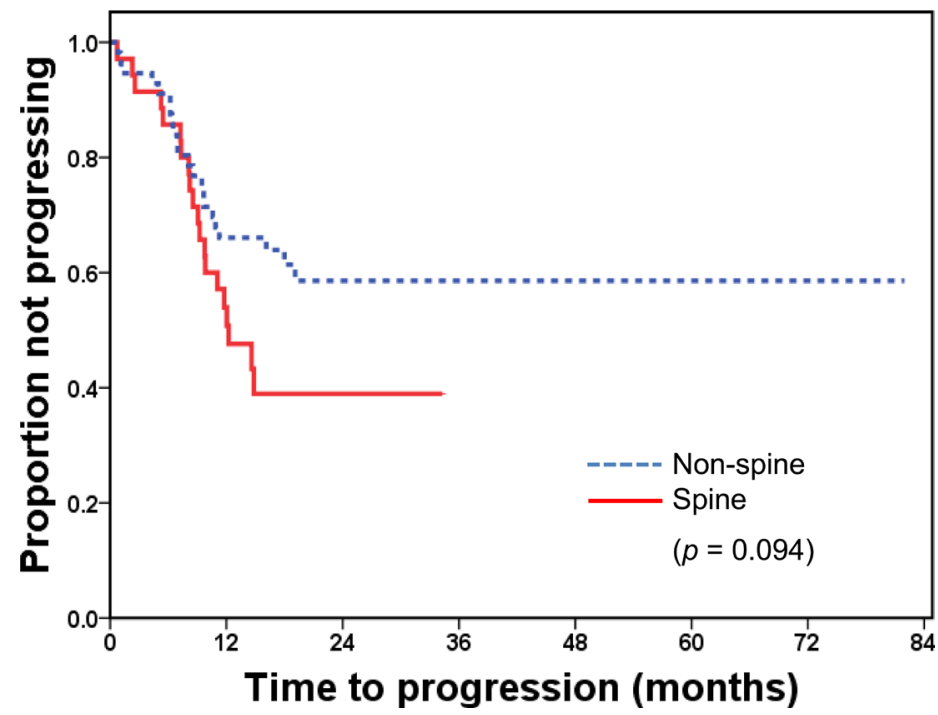

Figure 2: Time to progression after radiotherapy by the site of bone metastasis. 
Table 6: Acute and late toxicities by dose group

\begin{tabular}{|c|c|c|c|c|c|}
\hline \multirow[t]{2}{*}{ Toxicities } & \multirow[t]{2}{*}{ Grade } & \multicolumn{3}{|c|}{ No. of patients (\%) } & \multirow[b]{2}{*}{$P$-value } \\
\hline & & Total $(n=91)$ & High-dose $(n=45)$ & Low-dose $(n=46)$ & \\
\hline \multicolumn{6}{|l|}{ Acute } \\
\hline GI & 0 & $54(59.3)$ & $32(71.1)$ & $22(47.8)$ & 0.001 \\
\hline \multirow[t]{4}{*}{ (anorexia, nausea, vomiting) } & 1 & $18(19.8)$ & $8(17.8)$ & $10(21.7)$ & \\
\hline & 2 & $6(6.6)$ & $4(8.9)$ & $2(4.4)$ & \\
\hline & 3 & - & - & - & \\
\hline & $\mathrm{N} / \mathrm{A}$ & $13(14.3)$ & $1(2.2)$ & $12(26.1)$ & \\
\hline \multirow[t]{5}{*}{ Hematologic } & 0 & $6(6.6)$ & $3(6.7)$ & $3(6.5)$ & 0.174 \\
\hline & 1 & $28(30.8)$ & $14(31.1)$ & $14(30.4)$ & \\
\hline & 2 & $34(37.3)$ & $21(46.7)$ & $13(28.3)$ & \\
\hline & 3 & $22(24.2)$ & $7(15.5)$ & $15(32.6)$ & \\
\hline & N/A & $1(1.1)$ & $0(0)$ & $1(2.2)$ & \\
\hline \multicolumn{6}{|l|}{ Late } \\
\hline Myelopathy & 0 & $91(100)$ & $45(100)$ & $46(100)$ & 0.179 \\
\hline
\end{tabular}

HCC which has been reported to have a dose-response relationship with radiation $[10,12]$.

A few recent studies have reported the dose-response relationships of radiation and bone metastasis from HCC. Choi et al. showed that an elevated total irradiation dose could improve local control in spinal metastases from HCC. Patients in the higher BED (over $56 \mathrm{~Gy}_{10}$ ) group showed that the local control rate of bone metastasis was increased compared to the lower-dose group [14]. Kim et al. also reported significantly different radiologic response rates among different dose groups. In the high-dose group (>39 $\mathrm{Gy}_{10}$ ), the radiologic response was reported as $89.8 \%$; in the low-dose group, it was $66.3 \%$ [25] (Table 7). However, these studies did not report the time

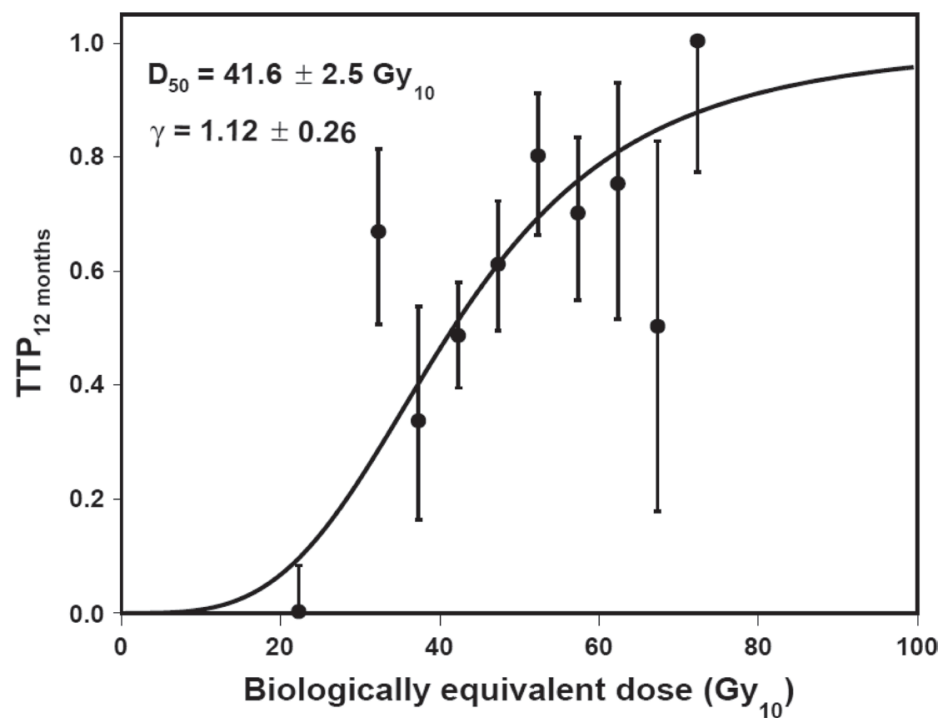

Figure 3: Tumor control probability 12 months after radiotherapy TTP, time to progression. 
Table 7: Summary of studies on dose escalations in bone metastasis from HCC

\begin{tabular}{lccccc}
\hline Study, year & $\begin{array}{l}\text { No. of patients } \\
\text { (No. of lesions) }\end{array}$ & $\begin{array}{l}\text { F/U (months) } \\
\text { Median (range) }\end{array}$ & $\begin{array}{l}\text { RT dose (Gy) } \\
\text { Median (range) }\end{array}$ & Local failure & Comments \\
\hline Choi et al., 2014 & 30 & 5.6 & $48.0(21.0-51.0)$ & $(p=0.019)$ & - \\
& $(42)$ & $(-)$ & $\mathrm{BED}_{10} \leq 56.0 \mathrm{~Gy}_{10}$ & $5 / 10$ & $1 / 20$ \\
Kim et al., 2011 & 103 & 6 & $30.0(8.0-45.0)$ & $(p=0.02)$ & - \\
& $(223)$ & $(0-46)$ & $\mathrm{BED}_{10}<39.0 \mathrm{~Gy}_{10}$ & $34 / 101$ & \\
& & & $\mathrm{BED}_{10} \geq 39.0 \mathrm{~Gy}_{10}$ & $5 / 49$ & \\
Current study & \multirow{2}{*}{22.8} & $40.0(20.0-66.0)$ & $(p=0.015)$ & $\mathrm{TTP}(\mathrm{mo})(p=0.016)$ \\
& $(91)$ & $(11.9-82.3)$ & $\mathrm{BED}_{10}<55.0 \mathrm{~Gy}_{10}$ & $27 / 46$ & 11.3 \\
& & & $\mathrm{BED}_{10} \geq 55.0 \mathrm{~Gy}_{10}$ & $15 / 45$ & 16.8 \\
\hline
\end{tabular}

Abbreviations: HCC, hepatocellular carcinoma; BED, biologically equivalent dose; TTP, time to progression.

to progression after radiotherapy by dose group. The time to progression is an important outcome for patients with bone metastases with regard to their quality of life or need for further treatment such as re-irradiation. In the present study, the high-dose group showed a significantly longer time to progression than the low-dose group. Moreover, according to the TCP analysis, the $52.8 \mathrm{~Gy}_{10}$ dose at the bone metastatic site brought about a $70 \%$ radiologic progression-free rate 12 months after radiotherapy. These findings suggest that a dose prescription of more than 55 $\mathrm{Gy}_{10}$ should be considered for radiotherapy in patients with bone metastasis from HCC, especially for those who are expected to live for more than 1 year.

We observed that the location of bone metastasis was a statistically significant factor for radiologic response. According to the analysis, time to progression was longer in non-spine metastasis that in spine metastasis. It can be assumed that the spinal cord is a major dose-limiting organ in case of bone metastasis in spine, since it is difficult to deliver a higher radiation dose in this region compared to other bone metastatic sites. Stereotactic body radiotherapy (SBRT) for spine metastasis is increasingly used given recent technical advances in radiotherapy technique; the highly sophisticated treatment approach should be considered in appropriate patients. Another significant factor for radiologic response is the use of chemotherapy on binary logistic regression. However, the adjusted odds ratio of systemic chemotherapy was 0.119 , which might be interpreted as chemotherapy having a negative effect on radiologic response. Nevertheless, due to the imbalance in number of patients per group (only 11 patients received chemotherapy), it is difficult to accurately define the actual clinical meaning of the relationship between chemotherapy and radiologic response for bone metastasis after radiotherapy. Further studies are necessary to clarify the relationship between these two treatment modalities for bone metastasis
This study had several limitations. First, we selected patients who were followed up for at least a year after radiotherapy. We understand that this could act as a significant confounding factor; however, to achieve the specific purpose of this study, we need to restrict the participant pool to those who had long-term imaging data in order to evaluate their time to progression and TCP so that we could develop recommendations for the optimal radiation dose in this clinical setting. Second, this study was a retrospective study, so it is possible that some data have been left out or the patients' symptomatic improvement or progression have been underestimated. Third, even though we used BED calculation in order to compensate for various dose schemes, some heterogeneity remained in the planning methods following time from 2D to IMRT, which could be another confounding factor. Despite these limitations, we believe that our data can provide useful information on treating patients with bone metastasis, especially if $\mathrm{HCC}$ is the primary tumor. According to our data, for patients with a favorable prognosis, the application of a higher dose should be considered to prevent tumor progression during the follow-up period and to reduce the probability of reirradiation at the same sites. On the other hand, for patients with a poor prognosis, we assume that low-dose and short-course irradiation is sufficient for short-term symptom palliation.

In conclusion, palliative radiotherapy for bone metastasis from HCC showed a dose-response relationship for the radiologic response rate and the time to progression. If a proper plan can exclude radiosensitive organs below the tolerance dose level using more sophisticated radiotherapy techniques such as SBRT or IMRT, high-dose irradiation (total BED larger than $55 \mathrm{~Gy}_{10}$ ) might be helpful for patients with a good prognosis. However, a prospective study is still necessary to confirm the appropriate radiation dose for bone metastasis from HCC. 


\section{MATERIALS AND METHODS}

\section{Patients}

From January 2004 to August 2012, 675 patients underwent palliative radiotherapy for bone metastasis from HCC at Asan Medical Center according to the database registry. Among these patients, we selected patients that met our research purpose using the following inclusion criteria: (1) patients who completed scheduled radiotherapy (50 patients were excluded owing to incomplete radiotherapy), (2) patients that were treated with multi-fraction radiotherapy regimens (8 patients were excluded), and (3) patients that had more than a year of follow-up with computed tomography (CT) or magnetic resonance imaging (MRI) of the treated bone metastatic sites (526 patients were excluded). We limited the study to patients who had long-term follow-up images in order to evaluate the response duration and time to progression after radiotherapy with these serial images. Therefore, 91 patients were included and we reviewed their medical records and imaging work-ups (CT, MRI, or positron emission tomography (PET)).

HCC was diagnosed based on pathologic confirmation or a characteristic tumor appearance on at least two imaging studies (including dynamic CT scans, dynamic enhanced MRI scans, and angiograms) and the presence of risk factors such as infection with hepatitis B or hepatitis $\mathrm{C}$ virus, and/or cirrhosis [15]. Bone metastases were diagnosed with imaging studies such as CT, MRI, PET, or bone scans, with histologic confirmation in some patients. A mass-forming metastasis was defined as an extra-osseous soft tissue mass with a clear boundary outside the bone [14].

\section{Radiotherapy}

Indications for external beam radiotherapy were symptomatic bone metastasis, spinal cord compression, high risk of pathologic fracture, or prophylactic treatment to sustain bone stability without development of the symptoms. Except for 16 patients $(17.6 \%)$ that were treated with two-dimensional treatment planning, threedimensional (3D) CT simulation was performed under free breathing with or without contrast media using a 16-slice CT (LightSpeed RT 16; GE Healthcare, Waukesha, WI, USA). Immobilizers such as a vacuum cushion were also used during the simulation to enhance reproducibility and accuracy. Gross tumor volume (GTV) was defined as the enhancing mass and osteolytic/osteoblastic changes on involved bone in planning $\mathrm{CT}$, which matched the lesion on the diagnostic images. Clinical target volume (CTV) included the GTV and the involved bony structures extended by 2 to $5 \mathrm{~cm}$ from the GTV to encompass the microscopic infiltrations of involved bone marrow according to the physicians' decisions. Planning target volume (PTV) was expanded 7 to $10 \mathrm{~mm}$ from the CTV. Radiotherapy planning was conducted using a 3D radiotherapy planning system (Eclipse; Varian, Palo Alto, CA, USA). Radiotherapy was delivered by 6- or 15MV X-rays from a linear accelerator (Varian, Palo Alto, CA). The total irradiation dose and fraction size were determined by adjacent organs, such as the spinal cord, stomach, and small or large bowel, in consideration of minimizing the radiotherapy-induced toxicity.

\section{Evaluation}

Most patients were regularly checked using dynamic contrast enhancing CT or MRI at 2- to 3 -month intervals to evaluate the primary intrahepatic tumor status. After radiotherapy, imaging work-ups for treated sites were performed at 1- to 3-month intervals. Additional examinations including simple radiography, bone scans, CT/MRI for other sites, or PET/CT were indicated according to the patients' symptoms. Using the Response Evaluation Criteria In Solid Tumors (RECIST) [16], we assessed the changes in the size of the massforming bone metastases and reported the best response after radiotherapy. In-field progression was defined as a $20 \%$ or higher increase in the largest diameter than in the best response status. The pain response was defined by referring to the guidelines of the International Bone Metastases Consensus Working Party palliative radiotherapy endpoints $[5,14,17]$. A complete response (CR) was defined as no pain after radiotherapy, partial response (PR) as a reduced numeric pain rating scale (NRS) score of more than 2 points, progressive disease as a disease with a more than 2-point higher pain score after radiotherapy, and stable disease (SD) as a status of neither PR nor PD. Adverse events related to radiotherapy were graded according to the Common Terminology Criteria for Adverse Events (CTCAE version 4.2).

\section{Statistical analysis}

The patients were divided into two groups according to their total irradiation dose for bone metastasis. Because the mean $\mathrm{BED}_{10}$ value of all the patients was $54.8 \mathrm{~Gy}_{10}$, we used $55 \mathrm{~Gy}_{10}$ as the cut-off point. Therefore, patients irradiated with a dose higher than 55 Gy $\mathrm{BED}_{10}$ were assigned to the high-dose group and the other patients were assigned to the low-dose group. The treatment responses and the times to the best radiologic response of the high-dose and the low-dose groups were compared using Student's $t$-test or a $\chi^{2}$ test. A one-way analysis of variance was utilized to examine the relationship between the changes of NRS scores and pain response.

The time to progression was defined as the period from the start date of the radiotherapy to the date of progression of the disease at an imaging workup, or to the date of symptomatic aggravation, or to the date of the 
last follow-up. The time to the best radiologic response was calculated from the start date of the radiotherapy to the date of the imaging workup that showed the best response. The times to progression of the two groups were calculated using the Kaplan-Meier method and compared through a log-rank test. $P$-value $<0.05$ was considered statistically significant. Prognostic factors for radiologic response were analyzed using binary logistic regression. Variables with a $p$-value $\leq 0.1$ in univariate analyses were included in a multivariable logistic regression model. The final model for response was determined by backward stepwise elimination procedures. All of the statistical analyses were performed using the Statistical Package for Social Science version 21 (SPSS Inc., Chicago, IL, USA).

The tumor control probability (TCP) was defined as the end-point of the control of tumor progression at 12 months after the radiotherapy. The $\mathrm{X}$-axis represents the prescribed total dose, the biologically equivalent dose (BED), and the Y-axis represents the probability of tumor control. The TCP for each bin was calculated using the Kaplan-Meier method. The quantification of the dose response to the tumor was estimated using a logistic model as follows:

$$
\mathrm{TCP}=\frac{1}{\left(1+\frac{\mathrm{D}_{50}}{\mathrm{D}}\right)^{4 / \gamma}}
$$

(D: total dose; $\gamma$ : slope of the curve; and $\mathrm{D}_{50}$ : dose that achieves a TCP of $50 \%$ for the prescribed dose)

$\mathrm{D}_{50}$ and $\gamma$ were estimated by a logit function. The 95\% confidence intervals (CIs) were calculated using the probability density function of the normal distribution. MATLAB R2011b was used for the formula and calculations [18].

\section{CONFLICTS OF INTEREST}

The authors have no conflicts of interest.

\section{REFERENCES}

1. Yu SJ. A concise review of updated guidelines regarding the management of hepatocellular carcinoma around the world: 2010-2016. Clin Mol Hepatol. 2016; 22:7-17.

2. Ferlay J, Soerjomataram I, Dikshit R, Eser S, Mathers C, Rebelo M, Parkin DM, Forman D, Bray F. Cancer incidence and mortality worldwide: sources, methods and major patterns in GLOBOCAN 2012. Int J Cancer. 2015; 136:E359-386.

3. Natsuizaka M, Omura T, Akaike T, Kuwata Y, Yamazaki K, Sato T, Karino Y, Toyota J, Suga T, Asaka M. Clinical features of hepatocellular carcinoma with extrahepatic metastases. J Gastroenterol Hepatol. 2005; 20:1781-1787.

4. Uchino K, Tateishi R, Shiina S, Kanda M, Masuzaki R, Kondo Y, Goto T, Omata M, Yoshida H, Koike K.
Hepatocellular carcinoma with extrahepatic metastasis: clinical features and prognostic factors. Cancer. 2011; 117:4475-4483.

5. Foro Arnalot $\mathrm{P}$, Fontanals AV, Galceran JC, Lynd F, Latiesas XS, de Dios NR, Castillejo AR, Bassols ML, Galan JL, Conejo IM, Lopez MA. Randomized clinical trial with two palliative radiotherapy regimens in painful bone metastases: 30 Gy in 10 fractions compared with 8 Gy in single fraction. Radiother Oncol. 2008; 89:150-155.

6. Hartsell WF, Scott CB, Bruner DW, Scarantino CW, Ivker RA, Roach M, 3rd, Suh JH, Demas WF, Movsas B, Petersen IA, Konski AA, Cleeland CS, et al. Randomized trial of short- versus long-course radiotherapy for palliation of painful bone metastases. J Natl Cancer Inst. 2005; 97:798-804.

7. Kaasa S, Brenne E, Lund JA, Fayers P, Falkmer U, Holmberg M, Lagerlund M, Bruland O. Prospective randomised multicenter trial on single fraction radiotherapy $(8 \mathrm{~Gy} \times 1)$ versus multiple fractions $(3 \mathrm{~Gy} \times 10)$ in the treatment of painful bone metastases. Radiother Oncol. 2006; 79:278-284.

8. Lutz S, Berk L, Chang E, Chow E, Hahn C, Hoskin P, Howell D, Konski A, Kachnic L, Lo S, Sahgal A, Silverman L, von Gunten C, et al. Palliative radiotherapy for bone metastases: an ASTRO evidence-based guideline. Int J Radiat Oncol Biol Phys. 2011; 79:965-976.

9. Sande TA, Ruenes R, Lund JA, Bruland OS, Hornslien K, Bremnes R, Kaasa S. Long-term follow-up of cancer patients receiving radiotherapy for bone metastases: results from a randomised multicentre trial. Radiother Oncol. 2009; 91:261-266.

10. Hayashi S, Tanaka H, Hoshi H. Palliative external-beam radiotherapy for bone metastases from hepatocellular carcinoma. World J Hepatol. 2014; 6:923-929.

11. Longo V, Brunetti O, D’Oronzo S, Ostuni C, Gatti P, Silvestris F. Bone metastases in hepatocellular carcinoma: an emerging issue. Cancer Metastasis Rev. 2014; 33:333-342.

12. Park HC, Seong J, Han KH, Chon CY, Moon YM, Suh CO. Dose-response relationship in local radiotherapy for hepatocellular carcinoma. Int J Radiat Oncol Biol Phys. 2002; 54:150-155.

13. Lee E, Kim TG, Park HC, Yu JI, Lim do H, Nam H, Lee H, Lee JH. Clinical outcomes of stereotactic body radiotherapy for spinal metastases from hepatocellular carcinoma. Radiat Oncol J. 2015; 33:217-225.

14. Choi Y, Kim J, Lee I, Seong J. Dose escalation using helical tomotherapy improves local control in spine metastases from primary hepatic malignancies. Liver Int. 2014; 34:462-468.

15. Yoon SM, Lim YS, Won HJ, Kim JH, Kim KM, Lee HC, Chung YH, Lee YS, Lee SG, Park JH, Suh DJ. Radiotherapy plus transarterial chemoembolization for hepatocellular carcinoma invading the portal vein: longterm patient outcomes. Int J Radiat Oncol Biol Phys. 2012; 82:2004-2011. 
16. Therasse P, Arbuck SG, Eisenhauer EA, Wanders J, Kaplan RS, Rubinstein L, Verweij J, Van Glabbeke M, van Oosterom AT, Christian MC, Gwyther SG. New guidelines to evaluate the response to treatment in solid tumors. J Natl Cancer Inst. 2000; 92:205-216.

17. Chow E, Hoskin P, Mitera G, Zeng L, Lutz S, Roos D, Hahn C, van der Linden Y, Hartsell W, Kumar E. Update of the international consensus on palliative radiotherapy endpoints for future clinical trials in bone metastases. Int $\mathrm{J}$ Radiat Oncol Biol Phys. 2012; 82:1730-1737.

18. Jang WI, Kim MS, Bae SH, Cho CK, Yoo HJ, Seo YS, Kang JK, Kim SY, Lee DH, Han CJ, Kim J, Park SC, Kim SB, et al. High-dose stereotactic body radiotherapy correlates increased local control and overall survival in patients with inoperable hepatocellular carcinoma. Radiat Oncol. 2013; 8:250.

19. van der Linden YM, Lok JJ, Steenland E, Martijn H, van Houwelingen H, Marijnen CA, Leer JW. Single fraction radiotherapy is efficacious: a further analysis of the Dutch Bone Metastasis Study controlling for the influence of retreatment. Int J Radiat Oncol Biol Phys. 2004; 59:528-537.

20. Sze WM, Shelley MD, Held I, Wilt TJ, Mason MD. Palliation of metastatic bone pain: single fraction versus multifraction radiotherapy: a systematic review of randomised trials. Clin Oncol (R Coll Radiol). 2003; 15:345-352.

21. Wu JS, Wong R, Johnston M, Bezjak A, Whelan T. Metaanalysis of dose-fractionation radiotherapy trials for the palliation of painful bone metastases. Int J Radiat Oncol Biol Phys. 2003; 55:594-605.

22. Chow E, Harris K, Fan G, Tsao M, Sze WM. Palliative radiotherapy trials for bone metastases: a systematic review. J Clin Oncol. 2007; 25:1423-1436.

23. Kim S, Chun M, Wang H, Cho S, Oh YT, Kang SH, Yang J. Bone metastasis from primary hepatocellular carcinoma: characteristics of soft tissue formation. Cancer Res Treat. 2007; 39:104-108.

24. Chen HY, Ma XM, Bai YR. Radiographic characteristics of bone metastases from hepatocellular carcinoma. Contemp Oncol (Pozn). 2012; 16:424-431.

25. Kim TG, Park HC, Lim DH, Kim CJ, Lee HB, Kwak KY, Choi MS, Lee JH, Koh KC, Paik WW, Yoo BC. Radiation therapy for bone metastases from hepatocellular carcinoma: effect of radiation dose escalation. J Korean Soc Ther Radiol Oncol. 2011; 29:63-70. 